\title{
Erratum to: Estimation of Sintering Kinetics of Oxidized Magnetite Pellet using Optical Dilatometer
}

\author{
T.K. SANDEEP KUMAR, NEELAKANTAN NURNI VISWANATHAN, \\ HESHAM H. AHMED, CHARLOTTE ANDERSSON, and BO BJÖRKMAN
}

DOI: $10.1007 / \mathrm{s} 11663-016-0844-1$

(C) The Minerals, Metals \& Materials Society and ASM International 2016

\section{Erratum to: METALLURGICAL AND MATERIALS TRANSACTIONS B, VOL. 46B, PP. 635-643, 2015, DOI: 10.1007/s11663-014-0273-y}

AUTHORS have used a new way for measuring bulk volume based on the image (pixel) analysis named as Light Table Imaging (LTI), and subsequently bulk densities and porosities. Authors lately found that there was a slight error in calibrating the scale (known distance) to pixel measurement and understand the need to communicate the error and subsequent corrections.

After correcting the calibration scale appropriately, the corresponding corrections have been implemented to evaluate the values of bulk volume, bulk density, porosity, sintering ratio and further kinetic parameters for all the pellets used in the study. The corrections have only changes the absolute values and does not affected or changed the understanding, outcome and conclusions of the study. Therefore, it is requested to incorporate the changes - Figures and Table by the corrected ones as mentioned below.
T.K. SANDEEP KUMAR, Doctorate Student, and BO BJÖRKMAN, Chaired Professor, are with the Department of Civil, Environmental and Natural Resources (SBN), Lulea University of Technology (LTU), 97187 Luleå, Sweden. Contact e-mail: kamesh. sandeep@1tu.se NEELAKANTAN NURNI VISWANATHAN, Visiting Professor is with the Department of Civil, Environmental and Natural Resources (SBN), Lulea University of Technology (LTU), and also Professor with the Department of Metallurgical Engineering \& Materials Science, Indian Institute of Technology Bombay (IITB), Mumbai 400076, India. HESHAM M. AHMED, Assistant Professor, is with the Department of Civil, Environmental and Natural Resources (SBN), Lulea University of Technology (LTU), and also with the Central Metallurgical Research \& Development Institute (CMRDI), Cairo, Egypt. CHARLOTTE ANDERSSON, Specialist/Senior Researcher, is with the Oxidation Metallurgy, Research \& Development, Luossavaara-Kiirunavaara AB (LKAB), Malmberget, 98381 Gällivare, Sweden.

The online version of the original article can be found under doi: 10.1007/s11663-014-0273-y.

\section{LIST OF CORRECTIONS}

1. Page 635, Abstract, Line 16/17: “....and reaction rate constant $\left(K^{\prime}\right)$ are estimated." should be replaced by "... and pre-exponential factor $\left(K^{\prime}\right)$ are estimated."

2. Figures which should be replaced with the corresponding ones as shown below:

i. Page 638, Fig. 2

ii. Page 639, Fig. 3

iii. Page 639, Fig. 4

iv. Page 640, Fig. 5

v. Page 640 , Fig. 6

vi. Page 641, Fig. 7

vii. Page 641, Fig. 8

viii. Page 642, Fig. 9

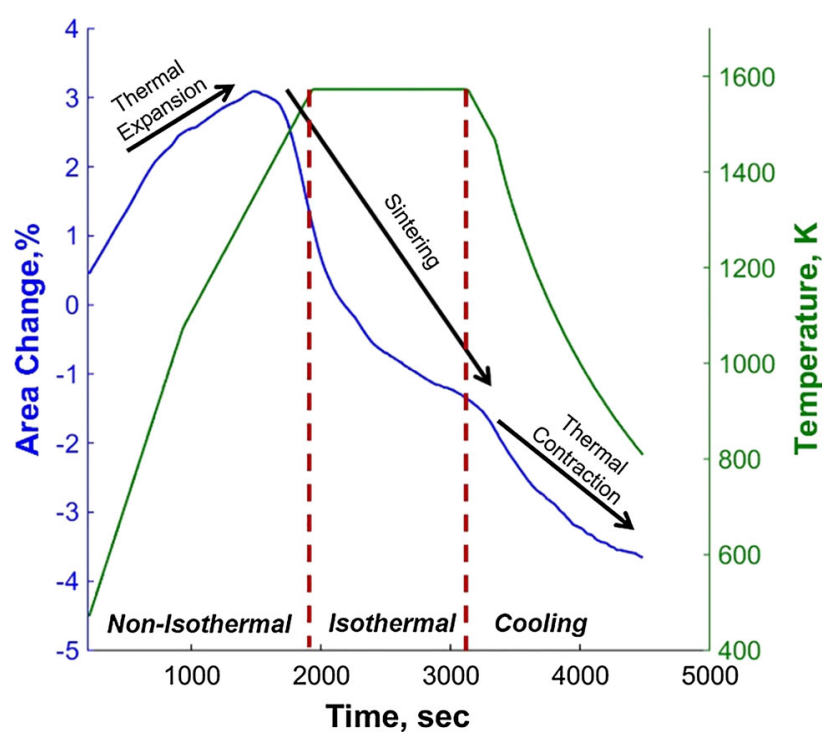

Fig. 2-Typical shrinkage curve obtained from Optical Dilatometer. 


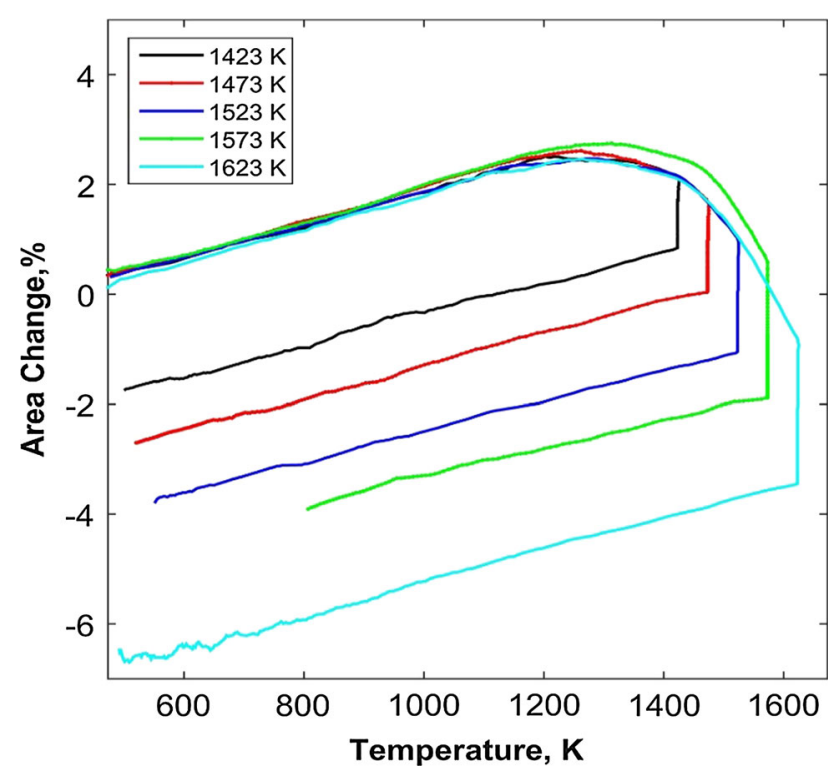

Fig. 3 - Change in area with respect to temperature for pellets exposed to different sintering temperatures for estimation of thermal coefficient of expansion for iron ore concentrate.

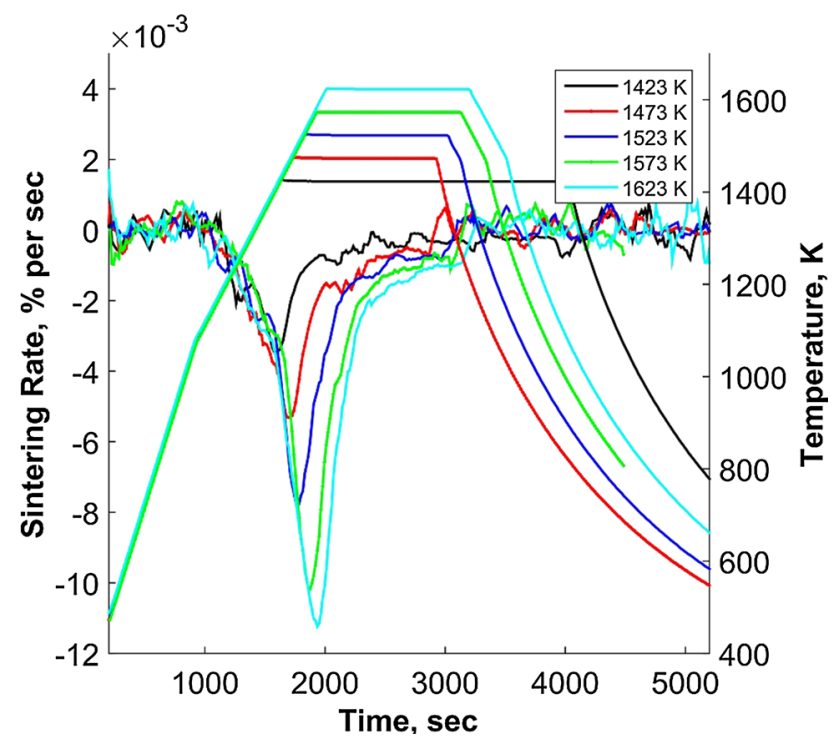

Fig. 4 - Sintering rates for pellets exposed to different sintering temperatures.

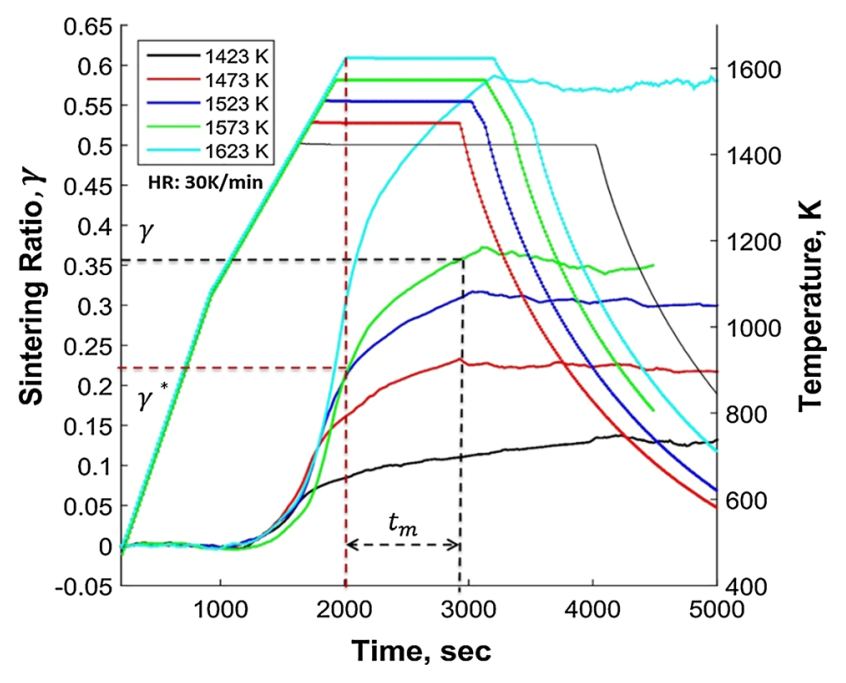

Fig. 5-Sintering ratio for pellets exposed to different sintering temperatures.

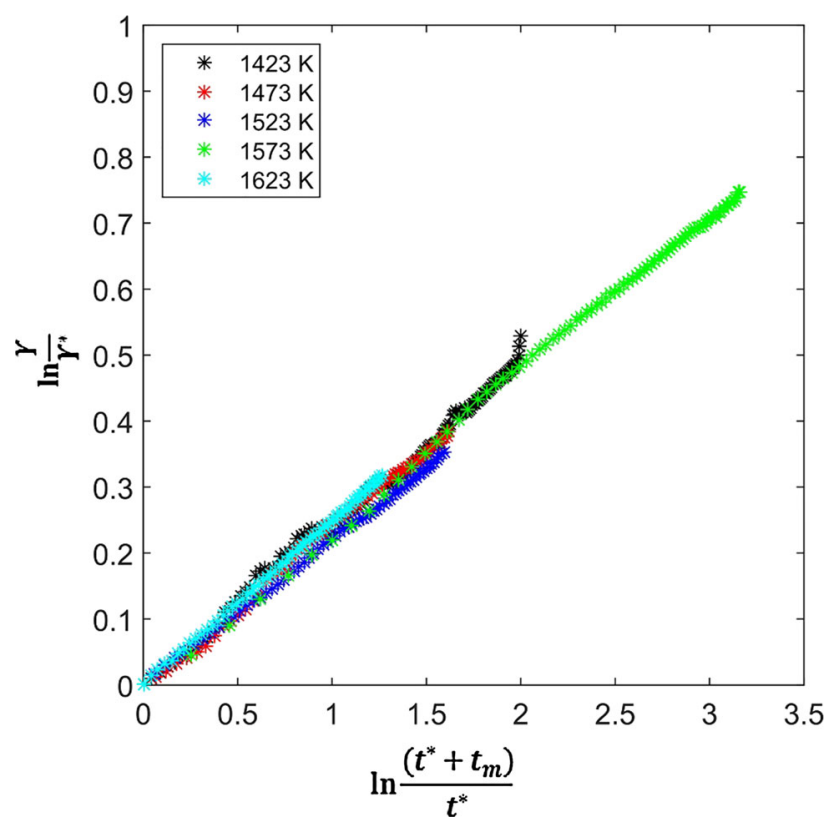

Fig. 6-Time exponent ' $n$ ' for oxidized magnetite pellets sintered at different temperatures. 


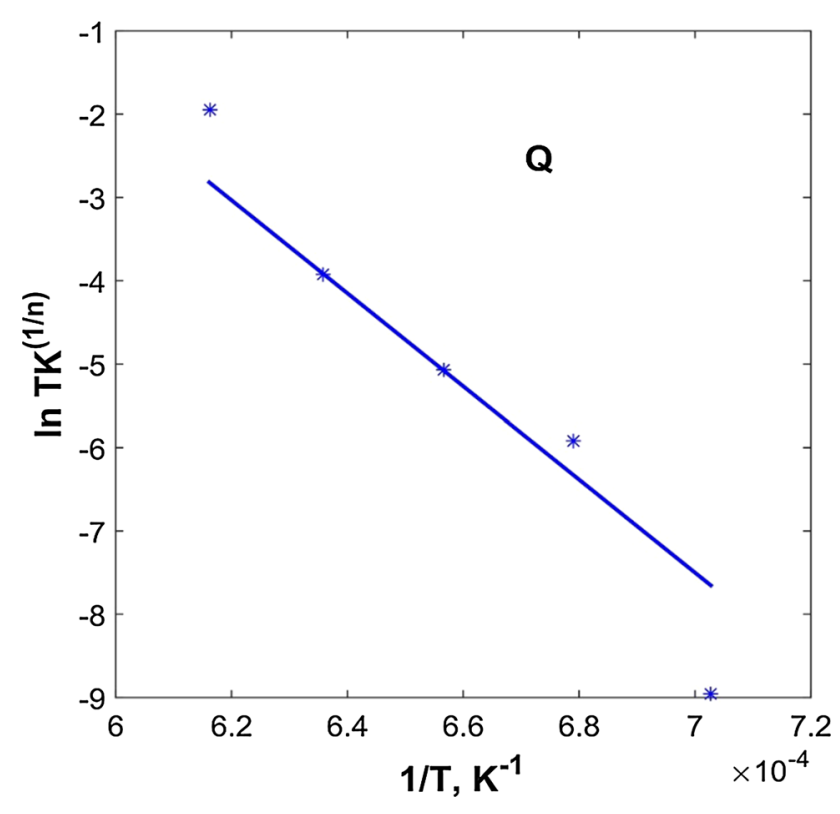

Fig. 7-Activation energy $(Q)$ and rate constant $\left(K^{\prime}\right)$ for sintering of oxidized magnetite pellets.

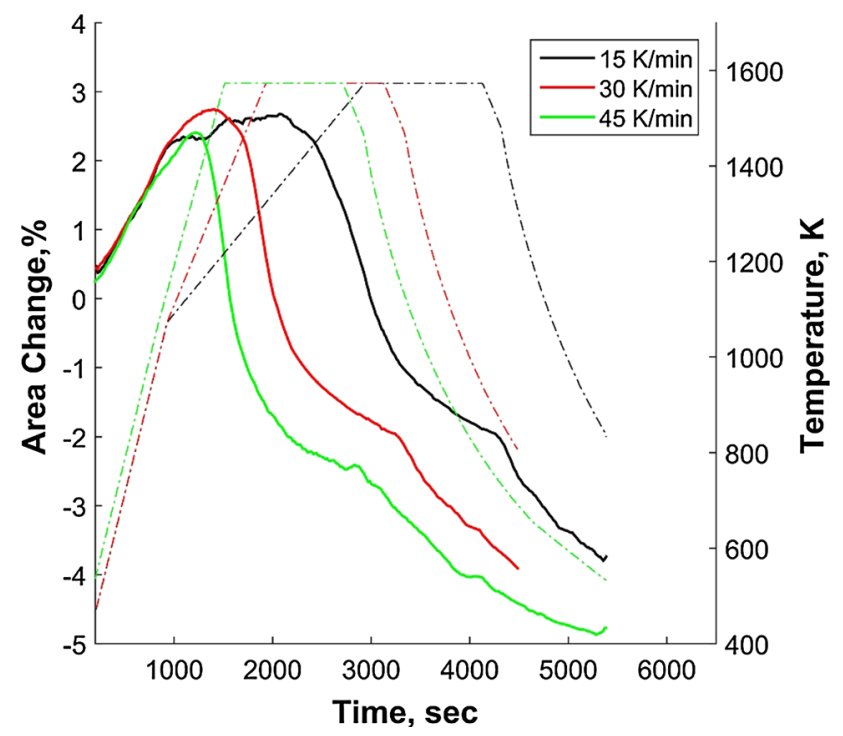

Fig. 8- Shrinkage curves for pellets exposed to different heating rates.
3. Page 641, Table III should be replaced by the corresponding table mentioned below.

4. Page 641, Line 11: “...were found to be 0.2099 and 2.57 pct, respectively" should be replaced by "...were found to be 0.2373 and 1.16 pct, respectively".

5. Page 642, Conclusions, Line 9: “....and rate constant $\left(K^{\prime}\right) \ldots$.. should be replaced by "....and pre-exponential factor $\left(K^{\prime}\right) \ldots$.

6. Page 642, Conclusions, Line 13: “...Q was found to be $509 \mathrm{~kJ} / \mathrm{mol}$." should be replaced by "...Q was found to be $464 \mathrm{~kJ} / \mathrm{mol}$."

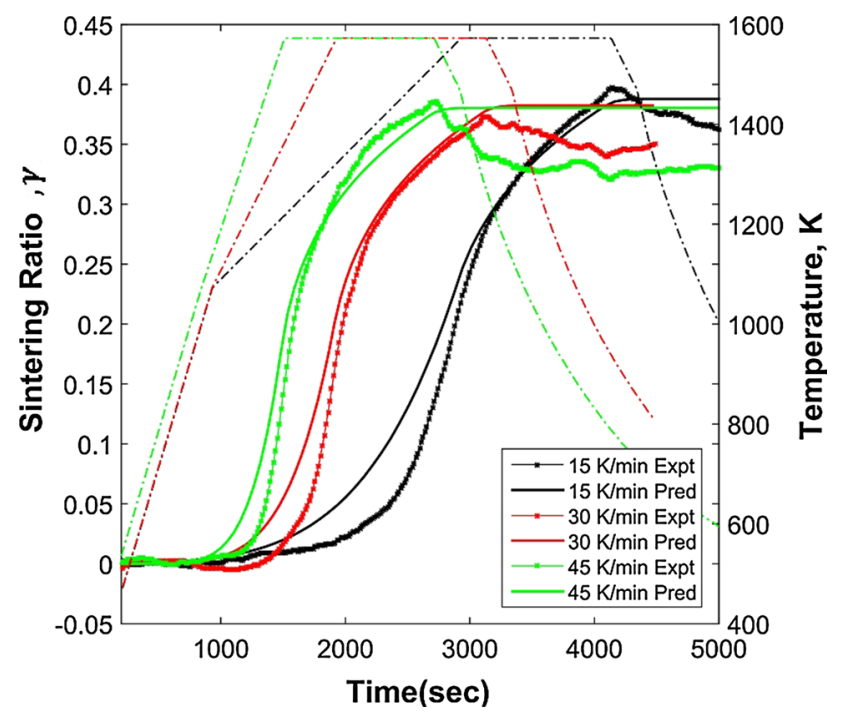

Fig. 9-Predicted and estimated sintering ratio for pellets exposed to different heating rates.

Table III. Sintering Kinetic Parameters

Isothermal Sintering

Pellet Temperature $\left[\mathrm{K}\left({ }^{\circ} \mathrm{C}\right)\right] \quad n$

\begin{tabular}{llll}
\hline P1 & $1423(1150)$ & 0.2438 & $Q=464 \mathrm{~kJ} / \mathrm{mol}$ \\
P2 & $1473(1200)$ & 0.2375 & $K^{\prime}=5.21 \times 10^{13} \mathrm{~s}^{-1}$ \\
P3 & $1523(1250)$ & 0.2187 & \\
P4 & $1573(1300)$ & 0.2371 & \\
P5 & $1623(1350)$ & 0.2496 & \\
\hline
\end{tabular}

